\title{
The prevalence and characteristics of suicidality in HIV/AIDS as seen in an African population in Entebbe district, Uganda
}

\author{
Eugene Kinyanda ${ }^{*}$, Susan Hoskins ${ }^{2}$, Juliet Nakku ${ }^{3}$, Saira Nawaz ${ }^{4}$ and Vikram Patel ${ }^{5}$
}

\begin{abstract}
Background: Suicidality in HIV/AIDS is not only a predictor of future attempted suicide and completed suicide, it is also associated with poor quality of life and poor adherence with antiretroviral therapy. This paper examines the prevalence and correlates of suicidality in HIV/AIDS in the African nation of Uganda.

Methods: A cross-sectional study was undertaken among 618 respondents attending two HIV clinics in semi-urban Uganda. A structured questionnaire was used to collect data on demographic, social, psychological and clinical factors. Correlates of suicidality were assessed using mulitvariable logistic regression.

Results: Prevalence of 'moderate to high risk for suicidality' (MHS) was $7.8 \%$ and that of life-time attempted suicide was $3.9 \%$. Factors associated with MHS at univariate analysis were: female gender, food insecurity, increasing negative life events, high stress score, negative coping style, past psychiatric history, psychosocial impairment, diagnoses of post-traumatic stress disorder, generalised anxiety disorder and major depressive disorder. Factors independently associated with MHS in multivariate models were female gender, increasing negative life events, a previous psychiatric history, and major depressive disorder.

Conclusions: These results are in agreement with the stress-vulnerability model where social and psychological stressors acting on an underlying diathesis (including previous and current psychiatric morbidities) leads to suicidality. These results identify potential targets to mitigate risk through treatment of psychiatric disorders and promoting greater adaptation to living with HIV/AIDS.
\end{abstract}

Keywords: HIV/AIDS, Suicidality, African population, Attempted suicide, Prevalence

\section{Background}

Suicidality, which for purposes of this study includes both significant suicidal ideation and attempted suicide, is one of the psychiatric problems associated with HIV/ AIDS [1]. A consideration of suicidality in HIV/AIDS is important not only because it predicts future attempted suicide and completed suicide, it has also has been associated with poor quality of life, poor adherence with ART (antiretroviral therapy) and non-disclosure of HIV status to significant others [1,2]. The few African studies on suicidality in HIV/AIDS have reported the following prevalence rates: $12.4 \%$ for suicidal ideation among patients attending a specialized HIV/AIDS clinic in pre-

\footnotetext{
* Correspondence: Eugene.Kinyanda@mrcuganda.org

${ }^{1} \mathrm{MRC/UVRI}$ Uganda Research Unit on AIDS \& Senior EDCTP Fellowship, P.O.

Box 49, Entebbe, Uganda

Full list of author information is available at the end of the article
}

ART Uganda; $17.1 \%$ for the 12 month prevalence of attempted suicide rate among HIV positive adolescent in pre-ART Uganda; $13 \%$ for current suicidal ideation among patients attending a specialized HIV/AIDS clinic in post-ART Uganda; and $16.8 \%$ for suicidality among HIV positive patients in South Africa [3-6]. All these studies reported on the prevalence of suicidality as a secondary finding, with none reporting on the correlates of suicidality.

Studies in the west have reported the following risk factors for suicidality in HIV/AIDS: socio-demographic factors (female gender, younger age, black ethnicity); psychiatric problems (substance abuse, major depressive disorder, antisocial personality disorder, previous attempted suicide, family history of a psychiatric disorder, family history of attempted suicide); psychosocial factors 
(heterosexual orientation, multiple HIV related loses, lack of social support, loss of employment or insurance cover, exhaustion of financial resources, physical and sexual abuse); and clinical factors (painful and disfiguring physical deterioration, suffering from lipodystrophyrelated symptoms, physical and psychological symptoms, AIDS diagnosis) [1,7-13]. In the only published African study to date that has looked at risk factors for suicidality in HIV/AIDS, Schlebusch and Vawda (2010) in South Africa reported the following risk factors: female gender, psychiatric disorders (major depressive disorder and substance abuse), partner relational problems, poor social support, fear of disclosure/stigmatization, socio-economic pressures, cognitive deficits (problems with cognitive flexibility, concentration and memory).

This paper examines the prevalence and correlates of suicidality in HIV/AIDS as seen in the African socio-cultural context of Uganda with a view to inform the development of mental health interventions for persons living with HIV/AIDS (PLWHA) on the African sub-continent.

\section{Methods}

\section{Study design}

This was cross-sectional study undertaken at two HIV clinics in the semi-urban district of Entebbe, Uganda. All consenting eligible HIV-infected patients attending the government health facilities of Entebbe District Hospital and Kigungu Health Centre III were continuously enrolled into this study. To be eligible for this study, the individual must have been registered with the study HIV clinics, 18 years or older, fluent in English or Luganda (the local language into which the study instruments had been translated) and not so physically and mentally sick as to be unable to complete the interview. Trained psychiatric nurses recruited from Uganda's National Psychiatric Referral hospital at Butabika conducted structured interviews to determine the prevalence and correlates of psychiatric disorders among the respondents.

\section{Data collection tools}

The data collection tool for the cross sectional study component consisted of various structured and standardized modules which were translated into Luganda (the local language spoken in the study area) and were administered by trained psychiatric nurses, these included:

1) Socio-demographic factors sex, age, marital status, highest educational attainment, religion, and employment status.

2) Social factors i) 'food insecurity' (assessed by the question, 'in the last month, did you or your family have enough food?'); ii) distance from the HIV clinic; iii) 'duration of awareness of HIV status'; iv) 'Negative life events score index,' constructed from items of the adverse life events module of the European Parasuicide Interview Schedule [14] that has previously been modified for the Ugandan situation by Kinyanda and colleagues (2005a) [15]. For this study, respondents were asked whether they had experienced each of these events in the last 6 months. Items were selected for inclusion in this study based on the relevance to the HIV social situation in Uganda. Items were included to reflect the key social relationships in an individual's life, namely parent (5 items), sibling (6 items), spouse/ lover ( 5 items), child(ren) (4 items) and the individual (7 items) with questionnaire items such as 'did your father die?' and 'have you been very ill ?'. A total score was generated to reflect the total number of life events reported, this scale had an $\alpha$ Cronbach of 0.82 in this study; v) 'Stress Score index,'

constructed by scoring each of the reported negative life events on a 3 point Likert scale where respondents were asked the question, 'how stressful did you find the event?' with possible responses being: $0=$ (not stressing $/$ minimal stressing), $1=$ (moderately stressing), $2=$ (severely stressing). $\mathrm{A}$ total score was generated where high scores reflected more stress; vi) 'Social support index', constructed from items of the social support module of the European Parasuicide Interview Schedule [14]. This scale has four sub-scales each with 4 items that assess the following social support dimensions: 'need for social support,' receive the required social support,', 'felt needed for social support' and 'felt was providing the required social support'. Each of the items in these sub-scales is scored on a 3 point Likert scale where $1=($ not at all), $2=($ to some extent), and $3=$ (yes, very much). Items of the subscale 'need for social support' were reverse scored so that higher scores on this indicated better social support just like the other three sub-scales. A total score was generated with higher scores reflecting better social support, the $\alpha$ Cronbach of this scale in this study was 0.84 .

3) Psychological and clinical factors i) Psychiatric disorder/problems was assessed using the M.I.N.I. neuropsychiatric interview (MINI Plus) [16] which is a modular DSM IV based structured interview. The psychiatric disorders modules used in this study were suicidality, major depressive disorder (excluding the suicidality items), alcohol use disorders, generalised anxiety disorder and post-traumatic stress disorder; ii) 'Negative coping style index' was constructed from variables of the Mental Adjustment to Cancer Scale (MAC) [17] whose items had been adapted to the local HIV situation. Each of this scale's 17 questionnaire items is scored 
on a 4-item Likert scale $1=$ (definitely does not apply to me), $2=$ (does not apply to me), $3=$ (applies to me), $4=$ (definitely applies to me). To score all the questionnaire items so that they are all in the same direction i.e. higher scores reflecting more negative coping style required that questionnaires items $(1,4,5,10,11,12,13,15,16)$ that are cast positively such as item 1: 'I have been doing things that I believe will improve my health e.g. changed my diet.' be reverse scored. A total score was generated so that higher scores reflected a more negative coping style, the $\alpha$ Cronbach of this scale in this study was 0.58 ; iii) 'past psychiatric history' was assessed by the question, 'have you ever suffered from any nervous or psychiatric condition?); iv) 'family history of psychiatric disorder'; v) 'neurocognitive impairment' assessed using the International HIV Dementia Scale [18]; vi) 'Psychosocial impairment index' constructed from the three variables 'in the last month, on how many days were your normal activities disrupted through illness?' (with responses scored as follows: none $=$ score 0 , one and above = score 1); 'how many times did you visit the health unit in the last month?' (with responses scored as follows: none $=$ score 0 , one and above = score 1), for how many days were you admitted to hospital in the last month?' (with responses scored as follows: none $=$ score 0 , one and above $=$ score 1$)$. A total score was generated so that higher scores reflected more impairment, this scale had an $\alpha$ Cronbach of 0.54 ; vii) most recent $C D 4$ count; and viii) body mass index.

\section{Statistical analysis}

A conceptual framework (Figure 1) based on the stressvulnerability model for suicide was specified a priori to guide the multivariate analyses and to avoid the problems of colinearity [19]. Statistical analysis was undertaken using both SPSS (reliability tests) and STATA. Logistic regression models were used to assess univariate associations between the dependent variable 'moderate to high risk for suicidality' (MHS) and independent variables, grouped in sets of demographic, social and psychological risk factors, with unadjusted and adjusted Odds ratio (adjusted for sex and age group, as a priori confounders) reported. The dependent variable in this paper is 'moderate to high risk for suicidality' (MHS) defined as a score of 9 and above on the B-items of the suicidality module of the M.I.N.I. neuropsychiatric interview (MINI Plus). The constituent items of the suicidality module of the M.I.N.I included items that assessed for previous attempted suicide, suicidal ideation and feelings of hopelessness. The rest of the investigated factors were considered as the independent variables.
The selection of the final model was done in stages, at each level of the framework. Variables whose age- and sex-adjusted (as a priori confounders) association with the outcome was significant at $\mathrm{p}<0.10$ were added to the model one by one, and those remaining associated at $\mathrm{p}<0.10$ were retained. Thus, social risk factors were considered one at a time, adjusting for independent demographic predictors, and psychological factors were considered one at time, adjusting for independent demographic and social predictors. In the final model, variables that were no longer associated with the outcome at $\mathrm{p}<0.10$ were allowed to drop. We did not find colinearity to be a problem using this approach.

\section{Ethical considerations}

The study obtained ethical approval from the Uganda Virus Research Institute's Science and Ethics Committee, the Uganda National Council of Science and Technology and the London School of Hygiene Ethics Committee. Study participants were invited to consent after being provided with adequate information about the study. Respondents found to have significant psychiatric problems were referred to the psychiatric department at Entebbe district hospital for further assessment and management.

\section{Results}

\section{Study population}

From $6^{\text {th }}$ May 2010 to $10^{\text {th }}$ August 2010, 680 patients attending the HIV clinics at Entebbe hospital and Kigungu health centre were screened and given appointments to be interviewed for this study. Of these 618 $(90.9 \%)$ were eventually enrolled into the study while 62 $(9.1 \%)$ failed to turn up for their interview appointment despite telephone reminders. Of those who were enrolled into the study, Entebbe district hospital contributed 531 (85.9 \%) while the smaller Kigungu Health Centre III contributed $87(14.1 \%)$. The two health facilities are located in the same district of Entebbe although the smaller health unit of Kigungu predominantly serves the fishing landing site of Kigungu while Entebbe hospital mainly serves the population in the urban centre. The study population of persons living with HIV/AIDS (PLWHA) was derived from the semi-urban and urban areas of Entebbe district who are better endowed socioeconomically when compared with the general population of PLWHA in Uganda who are predominately from poor peasant agricultural backgrounds.

\section{Characteristics of suicidality}

The prevalence of 'moderate to high risk for suicidality' (MHS) in this study was 7.8 \% (95 \% CI, $5.6 \%$ - $9.9 \%$ ) and that of life-time attempted suicide was $3.9 \%$ (95\% CI, $2.4 \%-5.4 \%)$. The number of previous suicide 


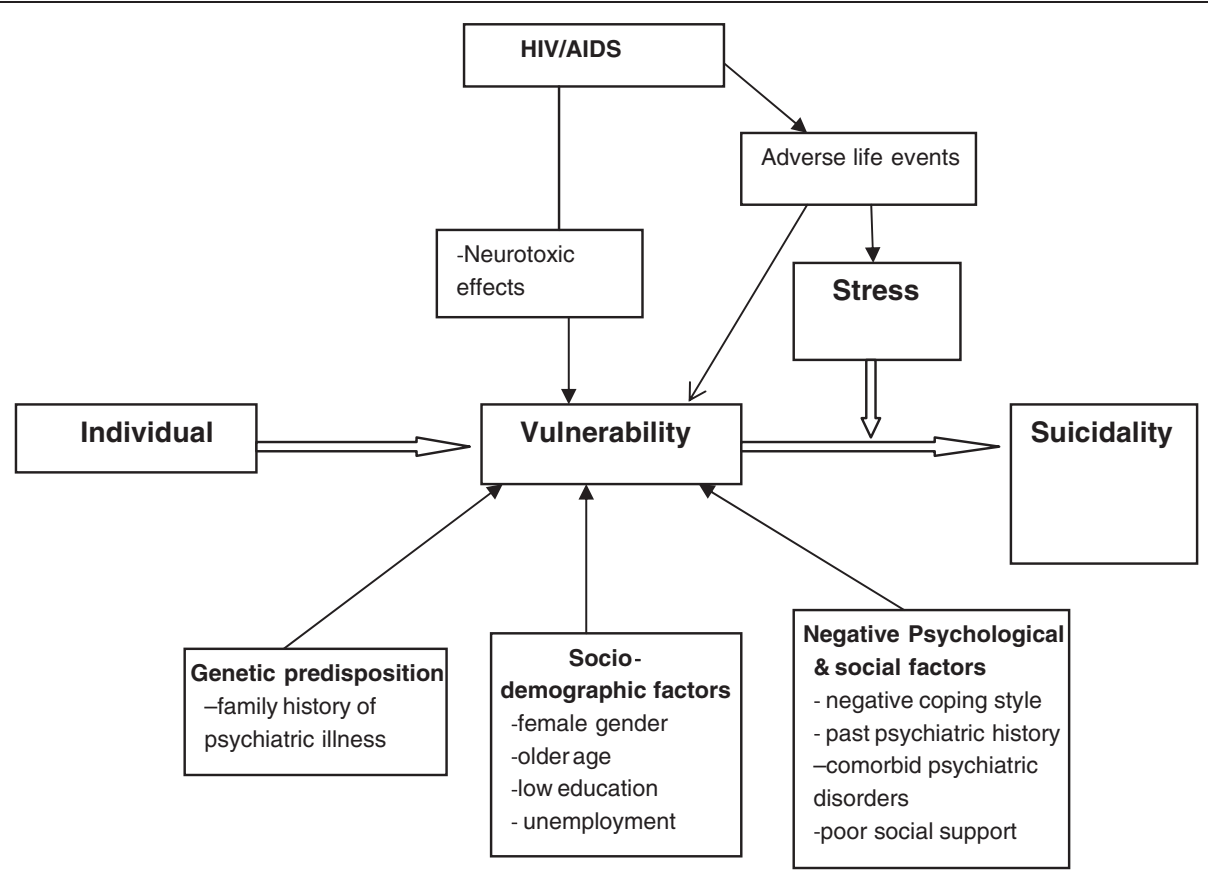

Figure 1 Conceptual framework based on the Stress-Diathesis Model (Mann et al., 1999) [19].

attempts reported $(n=22)$ were: 'one previous suicide attempt' 17 (77.3\%), 'two previous suicide attempts' 3 (13.6\%), 'three previous suicide attempts' $1(4.5 \%)$ and 'five previous suicide attempts' $1(4.5 \%)$. On 'methods of attempted suicide' used during the most recent attempt $(\mathrm{n}=21)$ these were: non-HIV medications 9 (42.9\%), HIV medications 2 (9.5\%), drowning 3 (14.3\%), organophosphate poisons 1 (4.8\%), hanging 1 (4.8\%), cutting 1 (4.8\%), jumping from a height 1 (4.8\%) and others not specified $3(14.3 \%)$.

\section{Socio-demographic correlates of MHS}

Table 1 depicts the socio-demographic characteristics, with 449 (72.7\%) females, and 456 (73.8 \%) patients in the 25-44 age band. Most (89.4\%) individuals had at least seven years of formal education but with only 53 (8.6\%) having gone on to attain a tertiary education. 275 (48.5\%) were married or currently living with someone, 75 (13.2 \%) widowed and 132 (23.3\%) separated or divorced. Most (42.4\%) were employed as small scale tradespersons, artisans or in the transport business (taxi drivers, taxi conductors and boda boda riders-motorcycle taxis).

On socio-demographic factors (Table 1 ), it was only female gender adjusted Odds Ratio (aOR) 2.26, $95 \% \mathrm{CI}=$ $1.06-4.84, \mathrm{P}=0.01$ ) that was significantly associated with MHS. Age, educational attainment, religion, marital status and occupation were not significantly associated with MHS. There were no differences in the prevalence of MHS by HIV clinic attended.

\section{Social factors associated with MHS}

Table 2, majority 358 (57.9\%) lived more than $5 \mathrm{Km}$ from the HIV clinic they were attending. Sixty nine (11.2\%) respondents reported food insecurity for themselves and their families. Majority 465 (75.6 \%) had known their HIV status for 13 or more months, with most $399(64.6 \%)$ on ART. On negative life events experienced in the last 6 months, 350 (56.6\%) reported 1-5 events; 191 (43.7\%) reported 6-10 events; 77 (12.5\%) reported $11+$ events.

After adjusting for age and sex, the social factors significantly associated with MHS were (Table 2): food insecurity (aOR 2.26, $95 \% \mathrm{CI}=1.06-4.84)$; increasing number of negative life events experienced in the last 6 months, $(\mathrm{aOR}=10.6,95 \% \mathrm{CI}=4.79-23.5$, for those reporting $11+$ events compared with those reporting 1-5 events) and increasing stress scores (aOR 9.69, $95 \% \mathrm{CI}=$ 3.28-28.7 for those with high scores compared with those with low stress scores). Factors not significantly associated with MHS were: 'distance from HIV clinic', 'when got to know HIV status', and 'being on ART' and social support.

\section{Psychological and clinical factors correlated with of MHS}

Table 3 depicts the psychological and clinical factors, 16 (2.6\%) had a past psychiatric history, while 120 (19.6\%) had a family history of psychiatric illness. 396 (64.1\%) had significant HIV associated neurocognitive impairment (a score of 10 or less on the International HIV Dementia Scale; Sacktor et al., 2005). The prevalence of 
Table 1 Socio-demographic correlates of suicidality

\begin{tabular}{|c|c|c|c|c|}
\hline & Number in study $(\mathrm{N}, \%)$ & Suicidality $(n, \%)$ & Unadjusted OR (95\% Cl) & Adjusted OR $(95 \% \mathrm{Cl})^{1}$ \\
\hline Sex & & & $P=0.003$ & $P=0.01$ \\
\hline Male & $169(27.3)$ & $5(3.0)$ & 1 & 1 \\
\hline Female & $449(72.7)$ & $43(9.6)$ & $3.47(1.35-8.93)$ & $3.06(1.17-8.02)$ \\
\hline Age (years) & & & $P=0.17$ & $P=0.46$ \\
\hline $19-24$ & $59(9.5)$ & $5(8.5)$ & 1 & 1 \\
\hline $25-34$ & $238(38.5)$ & $25(10.5)$ & $1.27(0.46-3.46)$ & $1.30(0.48-3.57)$ \\
\hline $35-44$ & $218(35.3)$ & $11(5.1)$ & $0.57(0.19-1.72)$ & $0.72(0.24-2.18)$ \\
\hline $45+$ & $103(16.7)$ & $7(6.8)$ & $0.79(0.24-2.60)$ & $1.00(0.30-3.35)$ \\
\hline Marital status & & & $P=0.81$ & $P=0.64$ \\
\hline \multicolumn{5}{|l|}{ Currently married/ } \\
\hline cohabiting & $275(48.5)$ & $24(8.0)$ & 1 & 1 \\
\hline Widowed & 75 (13.2) & $5(6.0)$ & $0.73(0.27-1.98)$ & $0.59(0.20-1.71)$ \\
\hline Separated/Divorced & $132(23.3)$ & $13(9.1)$ & $1.14(0.56-2.31)$ & $0.96(0.46-1.99)$ \\
\hline Single & $85(15.0)$ & $6(6.4)$ & $0.78(0.31-1.99)$ & $0.65(0.25-1.67)$ \\
\hline Education level & & & $P=0.59$ & $P=0.52$ \\
\hline No education & $65(10.5)$ & $7(10.8)$ & 1 & 1 \\
\hline Primary only & $289(46.8)$ & $20(6.9)$ & $0.62(0.25-1.52)$ & $0.61(0.24-1.53)$ \\
\hline \multicolumn{5}{|l|}{ Secondary and } \\
\hline above & $264(42.7)$ & $21(7.9)$ & $0.72(0.29-1.76)$ & $0.80(0.32-2.00)$ \\
\hline Religion & & & $P=0.28$ & $P=0.14$ \\
\hline Christian & $535(86.9)$ & $44(8.2)$ & 1 & 1 \\
\hline Moslem & $81(13.1)$ & $4(4.9)$ & $0.58(0.20-1.66)$ & $0.47(0.16-1.37)$ \\
\hline Employment Status & & & $P=0.43$ & $P=0.80$ \\
\hline Farmer/Fisherman & $97(15.7)$ & $6(6.2)$ & 1 & 1 \\
\hline Professional/Clerical & $43(7.0)$ & $23(7.0)$ & $1.14(0.27-4.78)$ & $1.06(0.25-4.56)$ \\
\hline \multicolumn{5}{|l|}{ Tradesperson/ } \\
\hline \multicolumn{5}{|l|}{ artisan/transport } \\
\hline worker & $262(42.4)$ & $20(7.6)$ & $1.25(0.49-3.22)$ & $0.96(0.36-2.57)$ \\
\hline \multicolumn{5}{|l|}{ Unemployed/house } \\
\hline Wife & $131(21.2)$ & $15(11.4)$ & $1.96(0.73-5.25)$ & $1.31(0.46-3.75)$ \\
\hline \multicolumn{5}{|l|}{ Others (including } \\
\hline students) & 84 (13.6) & $4(4.8)$ & $0.76(0.21-2.78)$ & $0.66(0.17-2.49)$ \\
\hline Clinic & & & $P=0.43$ & $P=0.39$ \\
\hline \multicolumn{5}{|l|}{ Entebbe distric } \\
\hline hospital & $531(85.9 \%)$ & $43(8.1 \%)$ & 1 & 1 \\
\hline Kigunga health centre & 87 (14.1\%) & $5(5.7 \%)$ & $0.69(0.27-1.80)$ & $0.66(0.25-1.73)$ \\
\hline
\end{tabular}

${ }^{1}$ adjusted for age group and sex.

psychiatric disorders/problems included major depressive disorder 50 (8.1\%), post traumatic stress disorder 10 $(1.6 \%)$, generalised anxiety disorder $5(0.8 \%)$ and alcohol dependency disorder 4 (0.7\%). On CD4 counts, 66 (12.5\%) had $<100$ cells/ $\mu \mathrm{L}, 159$ (30.2 \%) had 100-249 cells $/ \mu \mathrm{L}$ while 220 (35.6\%) had +350 cells $/ \mu \mathrm{L}$, the majority 387 (64.9\%) had a normal BMI.

Factors significantly associated with MHS were: increasing negative coping style index score (aOR 2.54, $95 \%$ $\mathrm{CI}=0.93-6.93$, for those with a high score compared with low scores), a past history of psychiatric illness (aOR 4.49,
$95 \% \mathrm{CI}=1.33-15.1$ ) psychosocial impairment (aOR 2.01, $95 \% \mathrm{CI}=1.07-3.76$ ), and a diagnosis of major depressive disorder, excluding suicidality items $(\mathrm{aOR}=30.3,95 \%$ $\mathrm{CI}=14.4-63.8)$. MHS was associated with post traumatic stress disorder and generalised anxiety disorder in the unadjusted analysis; however, the number with each diagnosis was too small $(\leq 10)$ to obtain reliable estimates of the association adjusted for confounders.

Factors not significantly associated with MHS were a family history of psychiatric illness, HIV- associated neurocognitive impairment, CD4 count or BMI. 
Table 2 Social correlates of suicidality

\begin{tabular}{|c|c|c|c|c|}
\hline & Number in study $(\mathrm{N}, \%)$ & Suicidality $(n, \%)$ & Unadjusted OR $(95 \% \mathrm{Cl})$ & Adjusted OR $(95 \% \mathrm{Cl})^{1}$ \\
\hline Food Security & & & $P=0.04$ & $P=0.05$ \\
\hline Enough & $549(88.8)$ & $38(6.9)$ & 1 & 1 \\
\hline Not enough & $69(11.2)$ & $10(14.5)$ & $2.28(1.08-4.81)$ & $2.26(1.06-4.84)$ \\
\hline Distance from HIV Clinic & & & $P=0.80$ & $P=0.76$ \\
\hline Less than $3 \mathrm{~km}$ & $94(15.2)$ & $8(8.5)$ & 1 & 1 \\
\hline 3 to $5 \mathrm{~km}$ & $166(26.9)$ & $11(6.6)$ & $0.76(0.30-1.99)$ & $0.72(0.28-1.89)$ \\
\hline More than $5 \mathrm{~km}$ & $358(57.9)$ & $29(8.1)$ & $0.95(0.42-2.15)$ & $0.91(0.40-2.08)$ \\
\hline When knew HIV Status & & & $P=0.92$ & $P=0.88$ \\
\hline Up to 12 months ago & $150(24.4)$ & $12(8.0)$ & 1 & 1 \\
\hline More than 12 months & $465(75.6)$ & $36(7.7)$ & $1.03(0.52-2.05)$ & $0.95(0.47-1.92)$ \\
\hline On ART & & & $P=0.75$ & $P=0.38$ \\
\hline Yes & $399(64.6)$ & $32(8.0)$ & $1.10(0.59-2.06)$ & $1.34(0.69-2.60)$ \\
\hline No & $219(35.4)$ & $16(7.3)$ & 1 & 1 \\
\hline Social Support & & & $P=0.09$ & $P=0.19$ \\
\hline Low & $188(30.4)$ & $20(10.6)$ & $1.71(0.94-3.12)$ & $1.52(0.82-2.79)$ \\
\hline High & $430(69.6)$ & $28(6.5)$ & 1 & 1 \\
\hline Negative life events & & & $\mathrm{P}<0.001$ & $\mathrm{P}<0.001$ \\
\hline $1-5$ events & $350(56.6)$ & $11(3.1)$ & 1 & 1 \\
\hline $6-10$ events & $191(43.7)$ & $16(8.4)$ & $2.82(1.28-6.20)$ & $2.63(1.19-5.83)$ \\
\hline $11+$ & $77(12.5)$ & $21(27.3)$ & $11.6(5.3-25.3)$ & $10.6(4.79-23.5)$ \\
\hline Stress Score index & & & $P<0.001$ & $\mathrm{P}<0.001$ \\
\hline Low (score 0) & $164(26.5)$ & $4(2.4)$ & 1 & 1 \\
\hline Medium (score 1-10) & $323(52.3)$ & $16(5.0)$ & $2.08(0.69-6.34)$ & $1.95(0.64-5.97)$ \\
\hline High (score $>10$ ) & $131(21.2)$ & $28(21.4)$ & $10.9(3.70-31.9)$ & $9.69(3.28-28.7)$ \\
\hline
\end{tabular}

${ }^{1}$ adjusted for age group and sex.

\section{Factors associated with MHS at multivariate analysis}

In the final multivariable model, female sex, increasing number of negative life events, a past psychiatric history, and a diagnosis of major depressive disorder were independently associated with MHS. Adjusting for HIV clinic in the final model did not change any of the ORs appreciably, indicating that clinic was not an important confounder. Post traumatic stress disorder and generalised anxiety disorder were not considered for inclusion in the final model because the numbers were too small.

\section{Discussion}

The paper sought to investigate the prevalence and the psychological, social and biological correlates of 'moderate to high risk for suicidality' (MHS) in HIV/AIDS in the African socio-cultural context. The principal finding of this study is that among ambulatory HIV/AIDS patients in the sub-Saharan African environment of Uganda, an increasing number of negative life events, past psychiatric history, and major depressive disorder were independent determinants of MHS. These results are in agreement with the stress-vulnerability model where social and psychological stressors acting on an underlying diathesis (including previous and current psychiatric morbidities) leads to suicidality [19].

The prevalence of a 'moderate to high risk for suicidality' (MHS) in this study was $7.8 \%$, a figure similar to that reported for suicidal ideation of $12.4 \%$ by Kinyanda (1998) in urban Pre-ART Uganda, 13 \% by Petruskin et al., (2005) in urban Post-ART Uganda and more recently of $8.8 \%$ by Rukundo (personal communication) in semi-urban south-western Uganda. A life-time attempted suicide rate of $3.9 \%$ reported in this study is similar to that of $3.1 \%$ reported by Rukundo (personal communication) in semi-urban south-western Uganda but much lower than the rates reported in western studies [7-11]. Some of this difference with western studies can be attributed to differences in the risk for suicidality inherent to the sub-population being investigated $[7,20]$. The sub-populations at risk for HIV in the west ('men who have sex with men' and IV drug users) have an inherently increased risk for suicidality independent of there HIV serostatus, this contrasts with the lower risk for suicidality associated with the general population derived heterosexually married sub-population (in this study sample, $48.5 \%$ ) who now constitute the biggest risk 
Table 3 Psychological and Clinical correlates of suicidality

\begin{tabular}{|c|c|c|c|c|}
\hline & Number in study $(\mathrm{N}, \%)$ & Suicidality $(n, \%)$ & Unadjusted OR (95\% Cl) & Adjusted OR $(95 \% \mathrm{Cl})^{1}$ \\
\hline Negative Coping Style index & & & $P=0.009$ & $P=0.02$ \\
\hline Low & $101(16.3)$ & $5(5.0)$ & 1 & 1 \\
\hline Medium & $322(52.1)$ & $18(5.6)$ & $1.14(0.41-3.14)$ & $1.08(0.39-3.03)$ \\
\hline High & 195 (31.6) & $25(12.8)$ & $2.82(1.05-7.61)$ & $2.54(0.93-6.93)$ \\
\hline Past Psychiatric History & & & $P=0.03$ & $P=0.03$ \\
\hline Present & $16(2.6)$ & $4(25.0)$ & $4.23(1.31-13.7)$ & $4.49(1.33-15.1)$ \\
\hline Family history of psychiatric Illness & & & $P=0.08$ & $P=0.09$ \\
\hline Present & $120(19.6)$ & $14(11.7)$ & $1.84(0.95-3.56)$ & $1.81(0.92-3.54)$ \\
\hline Neurocognitive Impairment & & & $P=0.30$ & $P=0.29$ \\
\hline Present & $396(64.1)$ & $34(8.6)$ & $1.39(0.73-2.67)$ & $1.41(0.73-2.70)$ \\
\hline Psychosocial Impairment & & & $P=0.03$ & $P=0.03$ \\
\hline Present & $318(51.5)$ & $32(10.1)$ & $1.99(1.07-3.70)$ & $2.01(1.07-3.76)$ \\
\hline Most Recent CD4 count (cells/ $\mu \mathrm{L}$ ) & & & $P=0.37$ & $P=0.30$ \\
\hline$<100$ & $66(12.5)$ & $4(6.1)$ & 1 & 1 \\
\hline $100-249$ & $159(30.2)$ & $15(9.4)$ & $1.61(0.51-5.06)$ & $1.52(0.48-4.81)$ \\
\hline $250-349$ & $81(15.4)$ & $9(11.1)$ & $1.94(0.57-6.60)$ & $1.69(0.49-5.85)$ \\
\hline $350+$ & $220(35.6)$ & $13(5.9)$ & $0.97(0.31-3.09)$ & $0.81(0.25-2.63)$ \\
\hline BMI Index & & & $P=0.60$ & $P=0.67$ \\
\hline Underweight & $56(9.2)$ & $4(7.1)$ & 1 & 1 \\
\hline Normal & $388(64.9)$ & $29(7.5)$ & $1.05(0.35-3.11)$ & $0.92(0.30-2.78)$ \\
\hline Overweight & $117(20.0)$ & $13(11.1)$ & $1.62(0.50-5.23)$ & $1.30(0.39-4.32)$ \\
\hline Obese & $35(5.9)$ & $2(5.7)$ & $0.79(0.14-4.54)$ & $0.57(0.10-3.46)$ \\
\hline Diagnosis of post traumatic stress disorder & & & $\mathbf{P}<0.001$ & \\
\hline Present & $10(1.6)$ & $8(80.0)$ & $56.8(11.7-276.4)$ & * \\
\hline Diagnosis of generalized anxiety disorder & & & $P=0.003$ & \\
\hline Present & $5(0.81)$ & $3(60.0)$ & $18.9(3.08-116.2)$ & * \\
\hline Alcohol dependency disorder & & & $P=0.29$ & \\
\hline Present & $4(0.65)$ & $1(25.0)$ & $4.02(0.41-39.4)$ & * \\
\hline Major depressive disorder & & & $\mathbf{P}<0.001$ & $\mathbf{P}<0.001$ \\
\hline Present & $50(8.1)$ & $27(54.0)$ & $30.6(15.1-62.0)$ & $30.3(14.4-63.8)$ \\
\hline
\end{tabular}

1 adjusted for age group and sex

* numbers too small to obtain reliable adjusted estimates.

category for new HIV infections in sub-Saharan Africa [20,21].

The majority of suicide attempters in this study (77.3\%) had done so once, similar results were reported by Kinyanda et al. (2005b) [22] among a general hospital sample of suicide attempters in urban Uganda where the rate for first time suicide attempters was $75 \%$. The main method of suicide attempt reported in this study was the use of medications (both HIV medications and others, $52.4 \%)$, this contrasts with the findings of Kinyanda et al., (2004) [23] who among a general hospital sample reported that the main method of attempted suicide was by poisons (mainly organophosphates, $65 \%$ ). In this study female gender conferred a three fold increased risk for suicidality relative to the male gender, a similar female predominance has been reported in South Africa
Table 4 Final Multivariate Model of risk factors for suicidality in HIV/AIDS

\begin{tabular}{|c|c|}
\hline & Adjusted OR \\
\hline & $(95 \% \mathrm{CI})^{1}$ \\
\hline$\overline{\text { Sex }}$ & $P=0.03$ \\
\hline Male & 1 \\
\hline Female & $2.86(0.99-8.27)$ \\
\hline Negative life events & $P=0.009$ \\
\hline $1-5$ events & 1 \\
\hline 6-10 events & $1.73(0.72-4.16)$ \\
\hline $11+$ & $4.35(1.72-11.0)$ \\
\hline Past Psychiatric Diagnosis & $P=0.04$ \\
\hline Present & $5.34(1.30-21.9)$ \\
\hline Major depressive disorder & $\mathbf{P}<0.001$ \\
\hline Present & $19.4(9.00-41.7)$ \\
\hline
\end{tabular}

adjusted for all factors listed in the table. 
[24] and France [9] but has not been observed in other western countries $[2,7]$.

Social factors associated with an increased risk for suicidality in this study included an increasing number of negative life events and the associated stress and food insecurity. Previous research has reported the following negative life events to be correlated with suicidality in HIV/AIDS: physical and sexual abuse, multiple HIVrelated losses, loss of employment or insurance cover, financial difficulties, and partner relational problems $[2,9,11,13]$. Food insecurity has previously been correlated with major depressive disorder in HIV/AIDS [25].

The psychological factors of a past psychiatric history and a diagnosis of major depressive disorder were independent correlates of MHS in this study. Bellini and Bruschi (1996) [7] in a review of studies on HIV infection and suicidality pointed out that, 'suicide attempts occur mainly in persons with a psychiatric history, previous attempted suicides or drug dependence'. More recent studies have also reported an association between suicidality in HIV/AIDS and psychological distress $[2,11]$ and major depressive disorder [12,13,23].

Other psychological factors reported to be correlated with NHS in this study were a negative coping style and psychosocial impairment. Previous studies have reported that the positive coping style/adjustment of 'spirituality' and 'a fighting spirit' to be protective against suicidality $[11,12,17]$. Pugh and colleagues (1993) studying a case series of HIV positive suicide in London observed that worsening physical health was a risk factor for suicide in HIV/AIDS [26]. In this study there was no evidence for the role of the neurotoxic effect of the HIV virus and for HIV associated neurocognitive impairment as correlates of NHS.

Limitations of this study include firstly, that the cross sectional nature of this study made it difficult to determine the direction of causality of the investigated factors and MHS. Therefore, there is need for longitudinal studies to establish the exact causal direction between the investigated variables and MHS. Secondly, the number of individuals with some of the diagnosed psychiatric disorders was too small to enable us to satisfactorily explore independent associations with MHS. Thirdly, the threshold used as a cut off point for 'moderate to high risk for suicidality' (MHS) was derived from the authors of the M.I.N.I. neuropsychiatric assessment and has never been locally validated in the African socio-cultural environment. However the items used to assess for risk for suicidality i.e. previous suicide attempt, suicidal ideation, hopelessness and degree of planning have previously been shown to be associated with suicidality in the African environment by the first author [20].

Fourthly, the use of the surrogate measure "risk for suicidality" instead of "suicidality" as the dependent variable may have reduced the importance of the correlates identified in this study.

Lastly, a number of the tools used to assess various psychosocial constructs have not been locally validated. These tools were however locally adapted through a forward and backward translation process and to minimise bias, only those tools with a minimum $\alpha$ Cronbach of 0.50 were used in the analysis for this paper.

\section{Conclusions}

These results are in agreement with the stress-vulnerability model where social and psychological stressors acting on an underlying diathesis (including previous and current psychiatric morbidities) leads to suicidality [19]. These results identify potential targets to mitigate risk through treatment of psychiatric disorders and promoting greater adaptation to living with HIV/AIDS [13]. Suicide prevention efforts in HIV/AIDS should therefore be directed at increased screening and treatment of psychiatric disorders in HIV/AIDS.

\section{Abbreviations \\ EK: Eugene Kinyanda; SH: Susan Hoskins; JN: Juliet Nakku; SN: Saira Nawaz; VP: Vikram Patel.}

\section{Competing interests}

The authors declare that they have no competing interests.

\section{Acknowledgements}

Study participants

Data and Statistics Section of the MRC/UVRI Uganda Research Unit on AIDS Kathy Baisley (LSHTM) for statistical support during the review of this manuscript.

Small Research Grants Initiative of the EfA Consortium (DfID funded RPC) who funded this study

Funding

Small Research Grants Initiative of the EfA Consortium (DfID funded RPC)

\section{Author details}

${ }^{1}$ MRC/UVRI Uganda Research Unit on AIDS \& Senior EDCTP Fellowship, P.O. Box 49, Entebbe, Uganda. ${ }^{2}$ Medical Research Council, Clinical Trials Unit, London, UK. ${ }^{3}$ Butabika National Psychiatric Referral Hospital, Kampala, Uganda. ${ }^{4}$ Dartmouth Institute, Dartmouth College, Hanover, USA. ${ }^{5}$ London School of Hygiene \& Tropical Medicine, UK \& Wellcome Trust Senior Research Fellow in Clinical Science, London, UK.

\section{Authors' contributions}

Concept: EK,SH, VP; Data collection: EK, SH, JN; Data analysis: EK, SN; First draft: EK, SH, JN, VP; Final revision: EK, SH, JN, VP, SN; All authors read and approved the final manuscript.

Received: 16 December 2011 Accepted: 18 June 2012

Published: 18 June 2012

\section{References}

1. Lonnqvist J: Physical illness and suicide. In Suicide-An unnecessary death. Edited by Wasserman D. London, UK: Martin Dunitz; 2001:93-98.

2. Sherr L, Lampe F, Fisher M, Arthur G, Anderson J, Zetler S, Johnson M, Edwards S, Harding R: Suicidal ideation in UK HIV clinic attenders. AIDS 2008, 22:1651-1658.

3. Kinyanda E: Frequency with which psychiatric disorder is associated with a positive HIV-1 serostatus as seen in persons attending a TASO clinic in Mulago. Kampala, Uganda: Masters thesis.: Makerere University; Department of Psychiatry; 1998. 
4. Musisi S, Kinyanda E: Emotional and behavioural disorders in HIV seropositive adolescents in urban Uganda. East Afr Med J 2009, 86(1):16-24.

5. Petrushkin A, Boardman J, Ovuga E: Psychiatric disorders in HIV- positive individuals in urban Uganda. Psychiatr Bull 2005, 29:55-458.

6. Olley BO, Zeier MD, Seedat S, Stein DJ: Post-traumatic stress disorder among recently diagnosed patients with HIV/AIDS in South Africa. AIDS Care 2005, 17(5):550-557.

7. Bellini M, Bruschi C: HIV infection and suicidality. J Affect Disord 1996, 38(2-3):153-164

8. Kelly B, Raphael B, Judd F, Kernutt G, Burnett P, Burrows G: Suicidal ideation, suicide attempts, and HIV infection. Psychosomatics 1998 39:405-415.

9. Preau M, Bouhnik AD, Peretti-Watel P, Obadia Y, Spire B, on behalf of the ANRS-EN12-VESPA Group: Suicide attempts among people living with HIV in France. AIDS Care 2008, 20(8):917-924.

10. Simoni JM, Nero DK, Weinberg BA: Suicide attempts among seropositive women in New York city. Am J Psychiatry 1998, 155:1631-1632.

11. Cooperman NA, Simoni JM: Suicidal ideation and attempted suicide among women living with HIV/AIDS. J Behav Med 2005, 28(2):149-156.

12. Lawrence ST, Willig JH, Crane HM, Ye J, Aban I, Lober W, Nevin CR, Batey DS, Mugavero MJ, McCullumsmith C, Wright C, Kitahata M, Raper JL, Saag MS, Schumacher JE: Routine, self-administered, touch-screen, computer-based suicidal ideation assessment linked to automated response team notification in an HIV primary care setting. Clin Infect Dis 2010, 50(8):1165-1173.

13. McDaniel JS, Brown L, Goodkin K, Cournos F, Lyketsos C, Working Group on HIV/AIDS: Practice guideline for the treatment of patients with HIV/AIDS. JAMA 2000, 157(11 Suppl):1-62.

14. Kerkhof AJFM, Bernasco W, Bille-Brahe U, Platt S, Schmidtke A: A WHO/ EURO Multicentre study on parasuicide. In European Parasuicide study interview schedule. EPSIS I version 6.2. Edited by Schiødt H, Aagaard B. The Netherlands: Department of Clinical and Health Psychology, University of Leiden; 1989.

15. Kinyanda $\mathrm{E}$, Hjelmeland $\mathrm{H}$, Musisi S: Life events in deliberate self-harm as seen in African population in Uganda. Crisis 2005, 26(1):4-11.

16. Sheehan $D$, Lucrubier $Y$, Sheehan $K H$, Amorim $P$, Janavs J, Weiller $E$, Herqueta T, Baker R, Dunbar GC: The Mini-International Neuropsychiatric Interview (M.I.N.I.): the development and validation of a structured diagnostic psychiatric interview for DSM-IVand ICD-10. J Clin Psychiatry 1998, 59(suppl 20):22-33.

17. Watson M, Greer S, Young J, Inayat Q, Burgess C, Robertson B: The development of a questionnaire measure of adjustment to cancer: the MAC. Psychol Med 1988, 18(1):203-209.

18. Sacktor NC, Wong M, Nakasujja N, Skolasky RL, Selnes OA, Musisi S, Robertson K, McArthur JC, Ronald A, Katibira E: The International HIV Dementia Scale: A new rapid screening test for HIV dementia. AIDS 2005, 19:1367-1374.

19. Mann JJ, Waternaux C, Haas G, Malone K: Towards a clinical model of suicidal behavior in psychiatric patients. Am J Psychiatry 1999, 156:181-189.

20. Marzuk PM, Perry W: Suicide and HIV: researchers and clinicians beware. AIDS Care 1993, 5(4):387-390.

21. Shafer LA, Nsubuga RN, Seeley J, Levin J, Grosskurth H: Examining the components of population-level sexual behaviour trends from 1993 to 2007 in an open Uganda cohort. Sex Transm Dis 2011, 38(12):697-704.

22. Kinyanda E, Hjelmeland H, Musisi S, Kigozi F, Walugembe J: Repetition of deliberate self-harm as seen in Uganda. Arch Suicide Res 2005, 9:333-344.

23. Kinyanda $E$, Hjelmeland $H$, Musisi S: Deliberate self-harm as seen in Kampala, Uganda. Soc Psychiatry Psychiatr Epidemiol 2004, 39:318-325.

24. Schlebusch L, Vawda N: HIV-infection as a self-reported risk factor for attempted suicide in South Africa. Afr J Psychiatry 2010, 13(4):280-283.

25. Wu DY, Munoz M, Espiritu B, Zeladita J, Sanchez E, Callacna M, Rojas C, Arevalo J, Caldas A, Shin S: Burden of depression among impoverished HIV-positive women in Peru. J Acquir Immune Defic Syndr 2008, 48(4):500-504.

26. Pugh K, O'Donnell I, Catalan J: Suicide and HIV disease. AIDS Care 1993, 5 (4):391-400.

\section{doi:10.1186/1471-244X-12-63}

Cite this article as: Kinyanda et al.: The prevalence and characteristics of suicidality in HIV/AIDS as seen in an African population in Entebbe district, Uganda. BMC Psychiatry 2012 12:63.

\section{Submit your next manuscript to BioMed Central and take full advantage of:}

- Convenient online submission

- Thorough peer review

- No space constraints or color figure charges

- Immediate publication on acceptance

- Inclusion in PubMed, CAS, Scopus and Google Scholar

- Research which is freely available for redistribution 